EGU2020-20841

EGU General Assembly 2020

(c) Author(s) 2020. This work is distributed under

the Creative Commons Attribution 4.0 License.

\title{
GPR and Microwave Tomography for the Assessment of Hollowed Tree Trunks
}

\author{
Fabio Tosti ${ }^{1}$, Francesco Soldovieri ${ }^{2}$, Ilaria Catapano ${ }^{2}$, Iraklis Giannakis ${ }^{1}$, Gianluca Gennarelli ${ }^{2}$, Livia \\ Lantini ${ }^{1}$, Giovanni Ludeno ${ }^{2}$, and Amir M. Alani ${ }^{1}$ \\ ${ }^{1}$ School of Computing and Engineering, University of West London (UWL), London, United Kingdom of Great Britain and \\ Northern Ireland (Fabio.Tosti@uwl.ac.uk; Iraklis.Giannakis@uwl.ac.uk; Livia.Lantini@uwl.ac.uk; Amir.Alani@uwl.ac.uk) \\ ${ }^{2}$ Institute for Electromagnetic Sensing of the Environment (IREA-CNR), National Research Council, I-80124, Naples, Italy \\ (soldovieri.f@irea.cnr.it; catapano.i@irea.cnr.it; gennarelli.g@irea.cnr.it; ludeno.g@irea.cnr.it)
}

The danger related to the structural stability of hollowed trees is a matter of wide discussion among the scientific community. Hollow cores in trees can extend to more than $50 \%$ of the total diameter [1] and, while the presence of a hollow tree might appear dramatic in terms of public safety, it is not always a cause of concern. It is known that hollow trees can form in many years or even decades [2] and, although the heartwood is effectively dead, the tree can continue to form sapwood on the exterior of the trunk to create a cylinder. However, robustness and structural support provided by this cylinder to the trunk and canopy above depend on the ratio of healthy to diseased tissue.

In this context, Ground Penetrating Radar (GPR) has proven to be an effective non-invasive tool, capable of generating information about the inner structure of tree trunks in terms of existence, location, and geometry of defects [3], [4]. Nevertheless, it had been observed that the currently available and known GPR-related processing and data interpretation methods and tools are able to provide only limited information on the tree inner structure.

In this study, we present a microwave tomographic approach for improved GPR data processing with the aim of detecting and characterising the geometry of hollowed trees. Tests were performed at Gunnesbury Park, London, UK. In particular, a number of 15 circular measurements were collected around the tree using the Aladdin $2 \mathrm{GHz}$ hand-held antenna system manufactured by IDS GeoRadar (Part of Hexagon), covering a height of $140 \mathrm{~cm}$. The tree was eventually felled and three sections were cut for validation purposes.

Results presented in this abstract are part of a major research project that the authors have undertaken for the last three years.

\section{Acknowledgements}

The authors would like to express their sincere thanks and gratitude to the following trusts, charities, organisations and individuals for their generosity in supporting this project: Lord 
Faringdon Charitable Trust, The Schroder Foundation, Cazenove Charitable Trust, Ernest Cook Trust, Sir Henry Keswick, Ian Bond, P.F. Charitable Trust, Prospect Investment Management Limited, The Adrian Swire Charitable Trust, The John Swire 1989 Charitable Trust, The Sackler Trust, The Tanlaw Foundation, and The Wyfold Charitable Trust. This paper is dedicated to the memory of our colleague and friend Jonathan West, one of the original supporters of this research project.

\section{References}

[1] Braithwaite, R.W. (1985). The Kakadu fauna survey: an ecological survey of Kakudu National Park. Canberra, Australia: Australian Parks and Wildlife Service.

[2] Ruxton, G.D. (2014). Why are so many trees hollow? Biology Letters, 10 (11).

[3] Giannakis, I., Tosti, F., Lantini, L., Alani, A.M. (2019). Diagnosing Emerging Infectious Diseases of Trees Using Ground Penetrating Radar, IEEE Transactions on Geoscience and Remote Sensing. doi: 10.1109/TGRS.2019.2944070

[4] Alani, A.M., Soldovieri, F., Catapano, I., Giannakis, I., Gennarelli, G., Lantini, L., Ludeno, G., Tosti, F. (2019). The Use of Ground Penetrating Radar and Microwave Tomography for the Detection of Decay and Cavities in Tree Trunks. Remote Sens., 11, 2073. 